\title{
ARTICLE
}

\section{Monte Carlo calculations for dose rate at indoors exposed by distributed Cs-137 activities}

\author{
Tsugio Yokoyama* and Shigetada Kobayashi \\ Toshiba Nuclear Engineering Services Corporation, 8 Shinsugita-cho, Isogo-ku, Yokohama-shi,Kanagawa-ken, 235-8523, Japan
}

\begin{abstract}
The correlation of dose rates inside of the typical Japanese house to different distributions of Cs-137 activities outside are calculated by using the Monte Carlo code MVP with its attached gamma cross section library for aiming at the planning of decontamination strategies and setting the priorities in order to decrease the amounts of waste soil effectively, which will be disposed and stored for a long time with shield. The study is summarized that (1) the decontamination of the roof is not effective in decreasing the dose rate of indoors when surrounding field is contaminated, (2) the plowing of wide area will decrease the dose rate by one tenth even if the depth is only $5 \mathrm{~cm}$, (3) the dose rate of the 2 nd floor is higher than that of the $1 \mathrm{st}$ floor in some decontamination cases.
\end{abstract}

\section{Keywords: Monte Carlo; Cs-137; dose rate; decontamination; plowing; MVP; indoor}

\section{Introduction}

The meltdown of three nuclear reactors at the Fukushima Daiichi nuclear power plant in Japan in March, 2011 contaminated large areas of farmland and forests as well as resident areas. The main radiation source of gamma ray is identified as cesium. The amount of cesium released is estimated to be about $10000 \mathrm{TBq}$ for Cs-137 according to the Japanese government accident report, which means the average fallout of Cs-137 on Fukushima prefecture is $0.73 \mathrm{MBq} / \mathrm{m}^{2}$ that highly depends on areas of the prefecture in actual [1]. While the Japanese government and local governments are planning to decontaminate the areas to reduce the dose of the residents and revive the towns, the work seems not in operation. One of the reasons is a huge amount of soil and plants contained in the soil that should be removed. The soils may cause another source of dose increase in the area, thus they cannot start the decontamination works as the residents do not accept the deposit site nearby them [2]. Many organizations, companies and volunteers are involved in the decontamination works and have measured the effect of decontamination on dose rate, though those work also need much manpower, time and many dosimeters to check the change of dose rates before and after the decontamination works. In the situation, it is very important to evaluate the relation of the change of dose rates and the way of decontamination where several methods are employed that includes the scraping of ground surface, the plowing of ground, the water

*Corresponding author. Email: tsugio1a.yokoyama@glb.toshiba.co.jp cleaning of roofs.

Monte Carlo calculation can evaluate the dose rate relatively easily under the various gamma source distributions in a complicated system with sufficient accuracy.

In the study, the correlation of dose rates inside of a typical Japanese house to different distributions of Cs-137 activities outdoors have been calculated by using the Monte Carlo code MVP [3] with its attached gamma cross section library for aiming at a planning of the decontamination area to be prioritized and decreasing the amounts of contaminated soil waste to be disposed from residential zones.

\section{Calculation method}

\subsection{Modeling for Monte Carlo code MVP}

A two-storied Japanese house is modeled as shown in Figure 1. For the simplicity, the house is modeled as a equivalent volume cylinder of $10 \mathrm{~m}$ in diameter and $5 \mathrm{~m}$ in height, above which a flat disk of $3 \mathrm{~cm}$ in thickness is attached that simulates the roof made of tiles. The outer boundary of the whole system filled with air is set at 1 $\mathrm{km}$ in height and $2 \mathrm{~km}$ in diameter, considering the sky shine effect while the ground thickness under the house is set at $10 \mathrm{~m}$, considering the ground shine. It is assumed that the activity source density of Cs-137 felled over the system is set at $1 \mathrm{MBq} / \mathrm{m}^{2}$, which is derived from the above mentioned average fallout density at Fukushima prefecture. The dose rate for different distributions of source and decontamination model has been evaluated for two disc-shaped zones inside the house. One zone is 
at $1 \mathrm{~m}$ high with $0.1 \mathrm{~m}$ thick from the ground level, which represents the dose rate at the 1 st floor, and the other is at $1 \mathrm{~m}$ high with the same thickness from the 2nd floor, which means $3 \mathrm{~m}$ high from the ground level. The gamma flux of each zone has been averaged horizontally over the whole area inside the cylindrical house.

\subsection{Gamma flux calculation by MVP}

The three dimensional Monte Carlo code MVP is used to evaluate the gamma flux in the house[3]. The continuous energy gamma source calculation has been conducted with one thousand million histories with the conditions shown in Table 1. The statistical error of the flux is estimated about $5 \%$ at $1 \sigma$ for each tally zone. The number density of the soil, roof tile and air used here are listed in Table 2 and Table 3.

Table 1. Calculation method and model.

\begin{tabular}{|c|c|}
\hline Items & Description \\
\hline Code & MVP \\
\hline Nuclear data & JENDL-3.3 attached gamma library \\
\hline System & $\begin{array}{l}\text { - } 2000 \mathrm{~m} \text { in diameter, } 1000 \mathrm{~m} \text { in height } \\
\text { - Ground thickness: } 10 \mathrm{~m} \text { in depth } \\
\text { - Air : Humidity at } 70 \% \text {, Temperature } \\
\text { at } 20 \text { degree Celsius } \\
\text { - Soil density }: 1.6 \mathrm{~g} / \mathrm{cm}^{3}(10 \mathrm{~m} \text { thick }) \\
\text { - Roof tile density }: 1.5 \mathrm{~g} / \mathrm{cm}^{3} \\
(3 \mathrm{~cm} \text { thick })\end{array}$ \\
\hline $\begin{array}{l}\text { Gamma } \\
\text { source }\end{array}$ & Cs-137 1MBq $/ \mathrm{m}^{2}$ (field and roof) \\
\hline Tally groups & 24 \\
\hline $\begin{array}{c}\text { No. of } \\
\text { histories }\end{array}$ & $\begin{array}{c}100 \mathrm{M} \text { ( Accuracy of gamma flux : } \\
\text { about } 5 \%(1 \sigma, \text { for } 200 \mathrm{KeV}))\end{array}$ \\
\hline
\end{tabular}

Table 2. Composition of soil of ground soil.

\begin{tabular}{ccc}
\hline Nuclide & Weight fraction & $\begin{array}{c}\text { Number density } \\
(/(\text { barn cm }))\end{array}$ \\
\hline H-1 & $2.10 \mathrm{E}-02$ & $2.0077 \mathrm{E}-02$ \\
C-12 & $1.60 \mathrm{E}-02$ & $1.2847 \mathrm{E}-03$ \\
O-16 & $5.77 \mathrm{E}-01$ & $3.4758 \mathrm{E}-02$ \\
Al-27 & $5.00 \mathrm{E}-02$ & $1.7855 \mathrm{E}-03$ \\
Si-28 & $2.71 \mathrm{E}-01$ & $9.3332 \mathrm{E}-03$ \\
\hline
\end{tabular}

Table 3. Composition of roof tile and air.

\begin{tabular}{cccc}
\hline \multicolumn{2}{c}{ Roof tile } & \multicolumn{2}{c}{ Air* } \\
\hline Nuclide & $\begin{array}{c}\text { Number } \\
\text { density } \\
(/(\text { barn cm }))\end{array}$ & Nuclide & $\begin{array}{c}\text { Number } \\
\text { density } \\
(/(\text { barn cm }))\end{array}$ \\
\hline $\mathrm{O}-16$ & $3.1707 \mathrm{E}-2$ & $\mathrm{H}-1$ & $8.0965 \mathrm{E}-07$ \\
$\mathrm{Si}$ & $1.0028 \mathrm{E}-2$ & $\mathrm{~N}-14$ & $3.7820 \mathrm{E}-05$ \\
$\mathrm{Fe}$ & $3.2244 \mathrm{E}-4$ & $\mathrm{O}-16$ & $1.1930 \mathrm{E}-05$ \\
$\mathrm{Al}$ & $3.5615 \mathrm{E}-3$ & - & - \\
\hline
\end{tabular}

*Humidity is assumed to be $70 \%$.

\subsection{Gamma data and dose rate conversion factors}

The conversion factor of gamma fluxes to dose rates employed is the 24 energy group table of ICRP Pub.74, thus the gamma fluxes in MVP calculation, where the gamma energy is treated as continuous energy model, are tallied to the 24 group bins.

\subsection{Dose rates for different sources}

Various decontamination methods are listed in Table 4. Case 2 is only the roof decontaminated. Case 3 is the field surrounding the house decontaminated while the roof is not. Case 4 is similar to the case 3 except the sources of the roof are flown down to the gutter as shown in Figure 2. Case 5 is only $1 \mathrm{~m}$ width around the house decontaminated. Case 6 and 7 are plowing of $5 \mathrm{~cm}$ in depth instead of decontamination. The results are (1) the dose rate for no decontamination is $3.4 \mu \mathrm{Sv} / \mathrm{h}$ and 3.1 $\mu \mathrm{Sv} / \mathrm{h}$ for each floor level ; (2) the complete decontamination of roof decreases the dose rate by about $10 \%$ only; (3) the complete decontamination of the field except the roof provides $0.21 \mu \mathrm{Sv} / \mathrm{h}$ and $0.45 \mu \mathrm{Sv} / \mathrm{h}$ for each level; (4) the complete decontamination of $1 \mathrm{~m}$ wide around the house decreases the dose rate to the same level as that of case 2; (5) the plowing of the ground by $5 \mathrm{~cm}$ in depth decreases the dose rate by about one third when the plowing range is $100 \mathrm{~m}$ around the house while that of the second floor is a little higher than that of $1 \mathrm{st}$ floor.

Table 4. Calculated dose rates at indoors for different decontamination cases.

\begin{tabular}{|c|c|c|c|}
\hline $\begin{array}{c}\text { Decontamination } \\
\text { Case }\end{array}$ & $\begin{array}{c}\text { 1st } \\
\text { Floor } \\
(\mu \mathrm{Sv} / \mathrm{h})\end{array}$ & $\begin{array}{l}\text { 2nd } \\
\text { Floor } \\
(\mu \mathrm{Sv} / \mathrm{h})\end{array}$ & Cs source positions \\
\hline No & 3.4 & 3.1 & $\begin{array}{l}\text { Uniform source } \\
\text { including source on } \\
\text { roof }\end{array}$ \\
\hline
\end{tabular}
2 Roof only
$\begin{array}{lll}2.9 & 2.7 \quad \text { Field }\end{array}$

3 Field only

0.21

0.45 Roof only

4 Field only

0.17

Sources on the roof are flown down to (type B) $5 \mathrm{~cm}$ wide gutter at peripheral

Only $1 \mathrm{~m}$

5 width of

peripheral

No roof source

field

Plowing by 5

$6 \mathrm{~cm}$ depth over all field

0.81

Uniform source for $5 \mathrm{~cm}$ thick in 1.31 soil.No source on roof.

Plowing by 5 cm depth over

7 100m width peripheral of the house
Ditto.

Surface source are $1.08 \quad 1.51$ on the field beyond $100 \mathrm{~m}$ width 


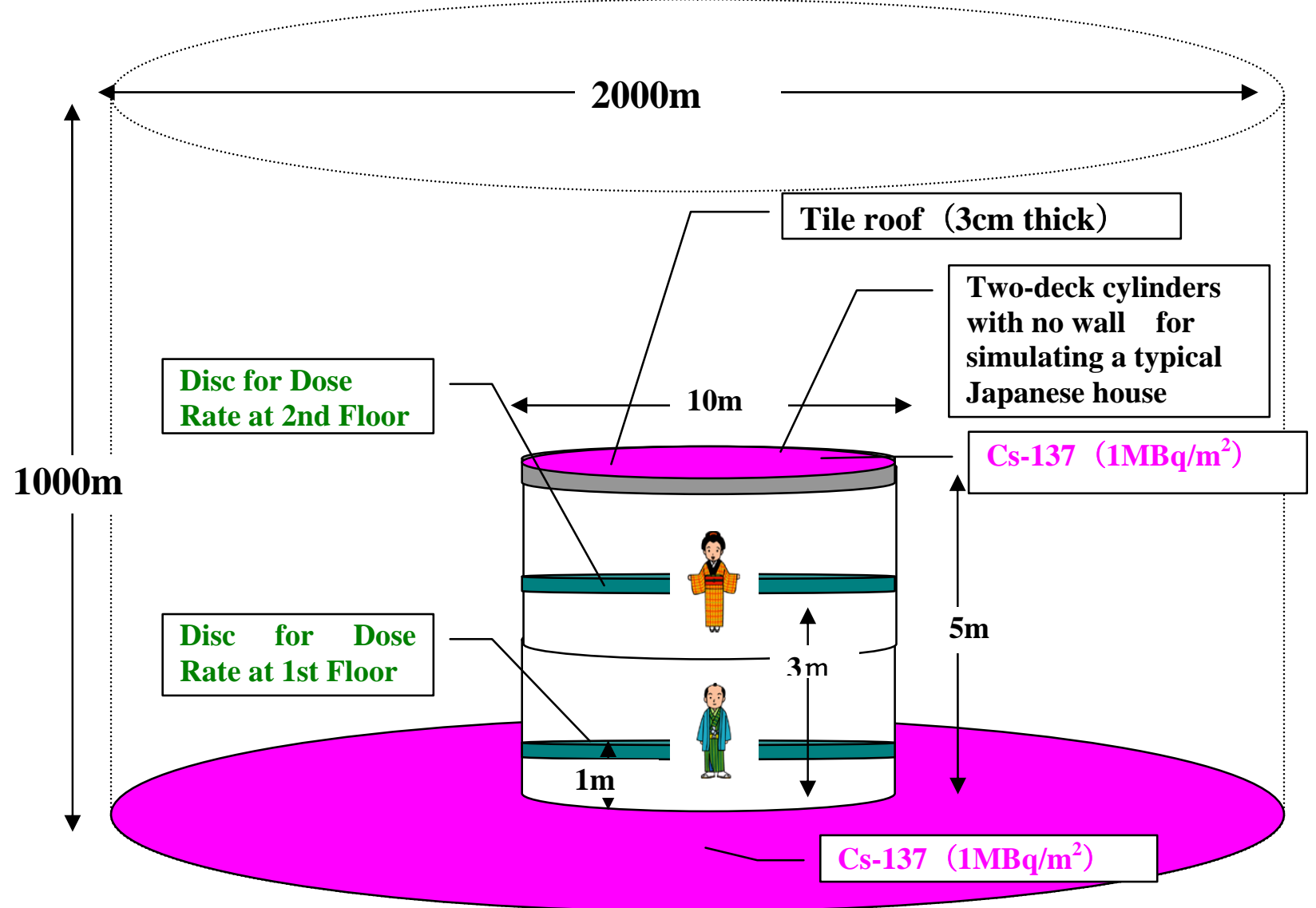

Figure 1. Calculation model of dose rates for typical Japanese houses.

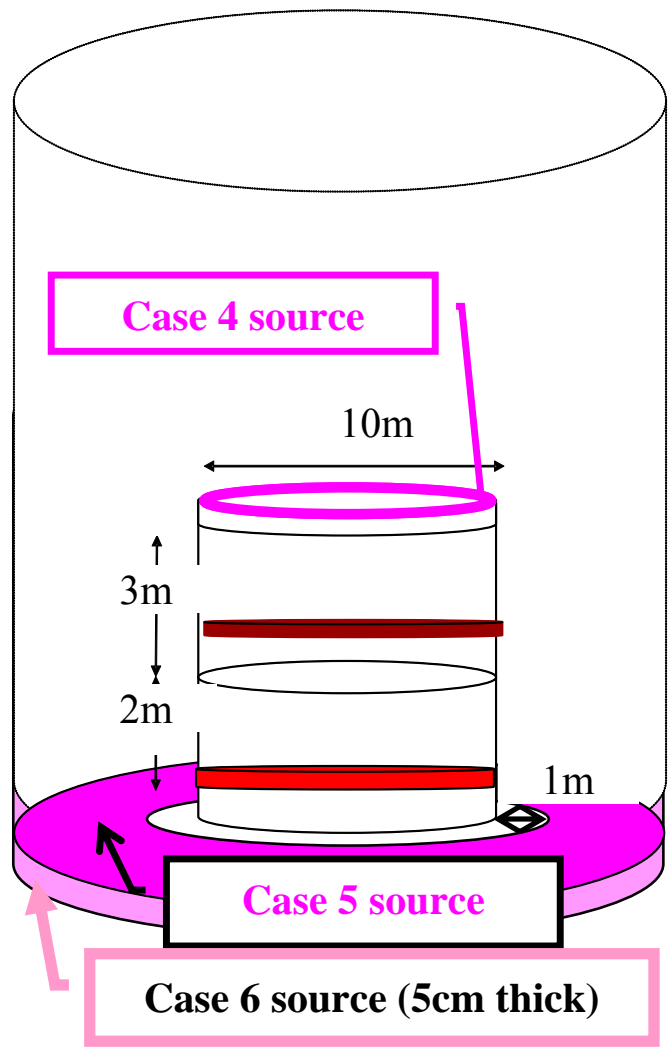

Figure 2. Calculation model of decontamination cases.

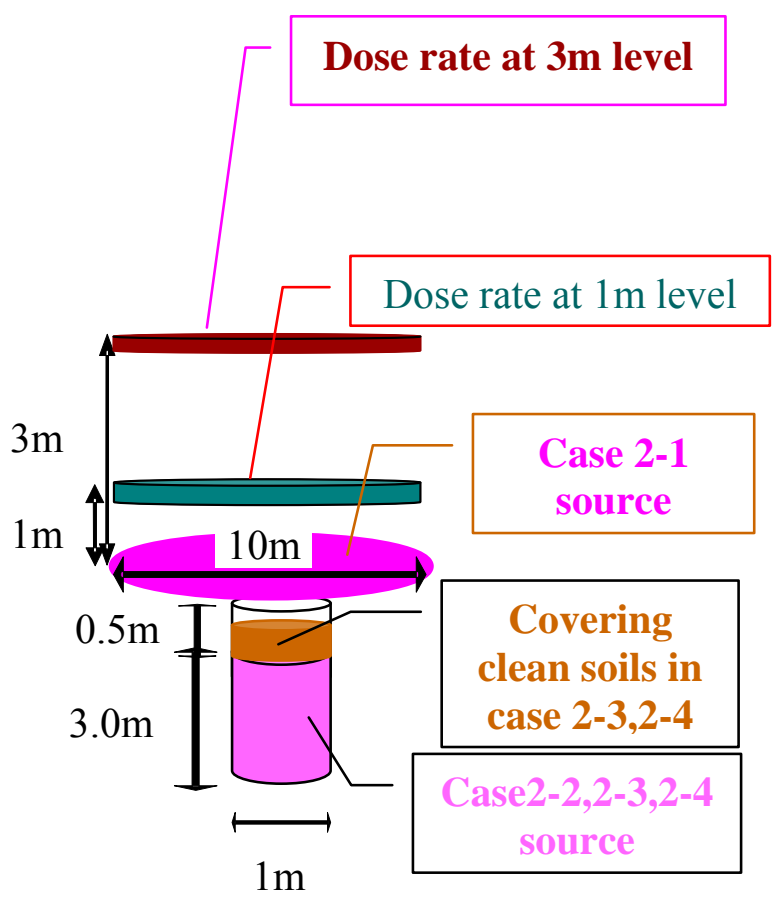

Figure 3. Calculation model for dose rate from deposit pit soil. 
The results are summarized that (1) the decontamination of the roof is not so effective to decrease the dose rate at indoors; (2) the plowing of wide area is effective even if the depth is only $5 \mathrm{~cm}$; (3) the dose rate of the 2 nd floor is higher than that of the $1 \mathrm{st}$ floor in some decontamination cases. This is due to a larger solid angle at the 2nd floor to the field sources than that at the 1 st floor.

\subsection{Validation of evaluation method}

For the validation of the method, the kerma of air at $1 \mathrm{~m}$ height has been evaluated for flat distributed Cs-137 sources. The dose rate of this method provides about $20 \%$ higher than that of the reference data [4] as shown in Table 5.

Table 5. Validation of MVP gamma calculation. ( $1 \mathrm{~m}$ in height, infinite Cs-137 source)

\begin{tabular}{cc}
\hline Data & $\begin{array}{c}\text { Kerma of air } \\
(\mathrm{nGy} / \mathrm{h}) \operatorname{per}\left(\mathrm{kBq} / \mathrm{m}^{2}\right)\end{array}$ \\
\hline Kerma by the method & $2.80(\mathrm{a})$ \\
IAEA-TECDOC-1162 & $2.37(\mathrm{~b})$ \\
$\mathrm{a} / \mathrm{b}$ & 1.18 \\
\hline
\end{tabular}

\subsection{Application to dose rate from deposit pit}

Contaminated soil that is collected may be deposited to pits dug at ground. As shown in Figure 3, the collected soil over the area of $10 \mathrm{~m}$ in diameter and $3 \mathrm{~cm}$ in depth is assumed to be deposited to the pit of $1 \mathrm{~m}$ in diameter and $3.5 \mathrm{~m}$ in depth. The dose rates at above levels of the pit are evaluated in the similar way. The result is shown in Table 6, where a few $\mathrm{cm}$ of covering clean soil is enough to decrease the dose rates to ordinary level.

\section{Conclusion}

The employed Monte Carlo calculation method evaluates the relation of dose rates indoors and sources outdoors in a short time (several minutes) with a high accuracy by recent PCs. This method can be applied to determine the ways and the priorities of decontamination strategies for decreasing dose rates effectively.

\section{Acknowledgements}

The authors wish to thank Prof. H. Nakamura for having recommended us to submit our study to ICRS12 and Prof. M. Kawai for his helpful comments to evaluate the deposit holes of soil.
Table 6. Estimation of dose rate of soil in pit.

\begin{tabular}{llccc}
\hline Case & Model & $\begin{array}{c}1 \mathrm{~m} \text { level } 3 \mathrm{~m} \text { level } \\
(\mu \mathrm{S} v / \mathrm{h})\end{array}$ & \multirow{2}{*}{$(\mu \mathrm{Sv} / \mathrm{h})$} & Notes \\
\hline & $\begin{array}{l}\text { Source of } 3 \mathrm{~cm} \\
\text { thick soil surfaces }\end{array}$ & & & \\
$2-1$ & $\begin{array}{l}\text { and } 10 \mathrm{~m} \text { in } \\
\text { diameter. }\end{array}$ & 1.13 & 0.388 & -
\end{tabular}

Removed soil from the surface for case $2-1$ is deposited to the pit

2-2 of $1 \mathrm{~m}$ dia. and $3.5 \mathrm{~m}$ deep with Amounts
of soil and upper $1 \mathrm{~m}$ height air space.

$0.202 \quad 0.0266^{\text {activities }}$ are conserved as case 2-1

Clean soil of 10 $\mathrm{cm}$ thick covered 2-3 on the soil in the pit at Case 2-2

\section{$0.0088 \quad 0.0012$ cover has} no activity

Clean soil of 50

2-4 $\mathrm{cm}$ thick covered on the soil in hole $0.0019 \quad 0.00027$ Ditto at Case 2-2

\section{References}

[1] Secretariat of the Investigation Committee on the Accidents at the Fukushima Nuclear Power Station, Investigation Committee on the Accident at the Fukushima Nuclear Power Stations, http://icanps.go.jp/eng/, (2012).

[2] Winifred Bird, As Fukushima Cleanup Begins, Long-term Impacts are Weighed, Yale Environment, http://e360.yale.edu/featureas/2482, (2012).

[3] T. Mori and M. Nakagawa, MVP/GMVP: General Purpose Monte Carlo Codes for Neutron and Photon Transport Code Based on Continuous Energy and Multi-Group Methods, JAERI-Data/Code 94-007 (1994).

[4] IAEA, Generic Procedures for Assessment and Response during a Radiological Emergency, IAEA-TECDOC-1162, (2000).ISBN4-938987-30-9 